\title{
Thoracopagus Conjoined Twins: A Case Report with Multiple
}

\section{Anomalies}

\section{Gopal Gupta1* ${ }^{*}$, Kamalpreet ${ }^{2}$, Namrata Katoch1, Parul Upadhayay ${ }^{1}$}

${ }^{1}$ Department of Anatomy, Pt. BD Sharma PGIMS, Rohtak, Haryana, India

${ }^{2}$ Department of Anatomy, Maulana Azad Medical College, Delhi

*Corresponding author: Dr Gopal Gupta, Department of Anatomy, Pt. BD Sharma

PGIMS, Rohtak, Haryana, India, Tel: +91-9416171937; E-mail: drgopalanatomy@gmail.com

\section{Case Report}

Volume 1 Issue 3

Received Date: November 12, 2017

Published Date: November 29, 2017

\section{Abstract}

Conjoined twins are rarely seen congenital anomalies associated with severe morbidity and mortality. Out of various forms, thoracopagus is most common type of conjoined twin anomaly. An unusual case of thoracopagus with various malformations had been received from department of pathology, which was kept there for an autopsy finding. As the case of thoracopagus, twins were united from upper thoracic region to umbilicus in the abdomen. Each twins shared a common heart, a common liver along with a shared proximal midgut loops. Most of the cases of thoracopagus are not suitable for surgical separation because of cardiac union and attempt to separate them is at the cost of one twin.

Keywords: Conjoined twins; Thoracopagus; Malformation

\section{Introduction}

Conjoined twins are rare congenital anomalies, which usually resulting from a defect of blastogenesis during early embryonic period. The overall incidence ranges from $1 / 50,000$ to $1 / 100,000$ of live births [1].

Out of all pattern of conjoined twins, thoracophagus conjoined twins are the most common one, in which there is face to face fusion of thorax along with variable involvement of abdominal part occurs [2].

There are variable numbers of theories for formation of thoracopagus twins but embryo logically, there are two different theories to explain the formation of conjoined twins. Firstly the 'Fission theory' which explains that, on $13^{\text {th }}$ day after fertilization the embryonic disc undergoes an incomplete separation [3]. While, the second 'fusion theory' stress on two separate mono-ovulatory embryonic discs undergoing a secondary association. Recently the "Fusion Theory" has been accepted well [4]. According to some authors, thoracopagus twins result from the union of the cardiac analgen and the septum transversum, leaving the cranial end of the early disc. As a result of which the development of head and neck including face and the brain becomes normal, but thorax get united [5].

Thus conjoined twins are identical twins and comes under the class of the monochorionic and monoamniotic (1-2\%) group. So it has been also believed that, in this two separate organizing centers which appear simultaneously in the single germ disc may overlap their differentiating influence to such an extent that two embryos are incompletely separated from each other.

The genetic basis for pathogenesis of conjoined twins is that, it's mainly due to misexpression of genes such as Goosecoid. This Goosecoid is responsible for initiation of 
primitive streak and ventralization of mesoderm [Langman Textbook of Medical Embryology]. The leftright asymmetries in these twins are regulated by a cascade of genes. A gene named sonic hedgehog which expressed in the notochord and serve as a midline barrier, represses or block the expression of left sided genes on the right embryo [6]. In a similar way, a gene 'snail' regulates right sidedness in the embryo. So these genes may also play certain role in formation of conjoined twins.

The morphological changes which usually occur in the thoracopagus twins are external and internal. Externally chest wall and abdomen is usually affected with some changes in gentalias and face. Internally in the thorax, there is one large complex heart with multiple ventricles and duplicate aortic arches. In abdomen, majority of cases are having large fused liver along with some shared part of gastrointestinal tract. So, in thoracopagus mainly the fusion of viscera is a factor for asymmetry. Liver is shared in almost all cases followed by heart but gastrointestinal tract is shared only in about half of the cases [7].

\section{Case Report}

The specimen of thoracopagus conjoined twin had been received from pathology department, which was preserved in $10 \%$ formalin for autopsy purpose. After the ethical approval it was brought to the anatomy department for the purpose of dissection and study. The history has been taken from the department of gynecology and obstetrics department of PGIMS, Rohtak. History revealed that it was a case of still born 34 Weeks twin pregnancy which were born to a $\mathrm{G}_{2} \mathrm{P}_{0} \mathrm{~A}_{1}, 30$ years old Indian-Asiatic Women with no history of previous twin pregnancy in her family, in both maternal and paternal side. The pregnancy was uncomplicated with no history of any kind of infection, ingestion of drug or exposure to radiation during pregnancy.

The history taken from gynecology and obstetrics department also revealed that, stillborn infants were approximately of equal in size and their combined weight was 2.8 Kilograms. The specimen was immediately put in $10 \%$ formalin and sent to pathology department for academic interest and to analyze various anomalies.

As per our findings the external morphological details were, the heads were hyper-extended and both twins have kyphosis. They were conjoined along the midline of the thorax to the umbilicus, which was single for both the twins. Out of two babies, one was having cleft lip. On cut section umbilical cord showed five vessels.

To look for further details and study purpose, baby having cleft lip with cleft palate has been labeled as Twin$A$ and another with normal face labeled as Twin-B (Figure 1). There were many features which were common in both the twins but lot more features were varied in both the twins which were described separately in there description.

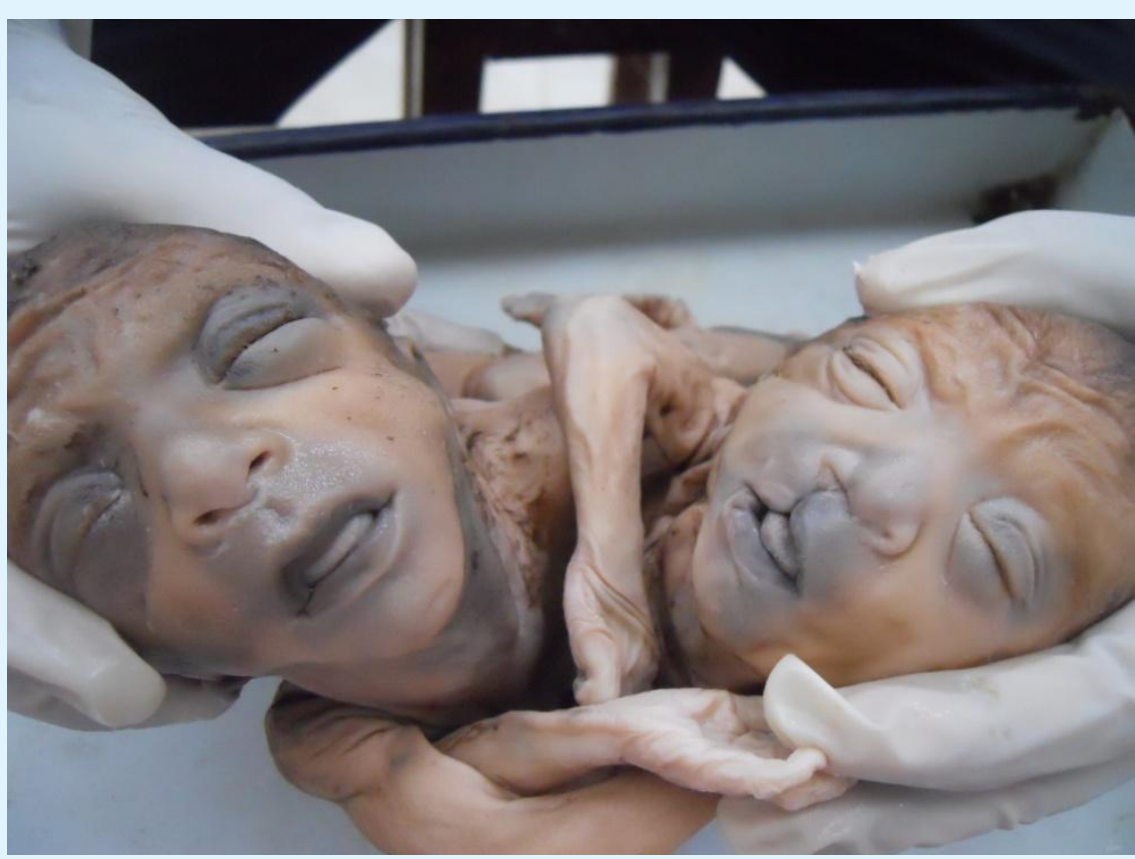

Figure 1: Image of a Thoracopagus twins after vaginal delivery at 34 weeks of Gestation. 


\section{Thoracopagus Conjoined Twins}

Now the common feature regarding thorax among both the twins were, fused Manubrium Sternii with Bifid sterna bodies and xiphoid process. This resulting into single shared thoracic cavity with common inferior mediastinum, which contains single pericardial sac with multiple chambered fused heart.

There were features which were entirely different in both the twins and they are described separately for each twin.

\section{For Twin-A with Cleft Lip (Figure 2)}

a. Both pulmonary artery and aorta were originated from a single ventricle. Both these vessel were otherwise normal but fused at proximal ends and separate at distal ends with incomplete spiral septum.

b. Anomalies of systemic veins present with presence of both right \& left superior vena cava. Right superior vena cava received innominate, azygos \& jugular veins on right Side. Persistent left superior vena cava, received hemiazygous vein and jugular veins of right side \& entered in atrium at the site of large dilated coronary sinus.

c. Inferior vena cava was separate for twin-A and open into common atrium.

d. Umbilical cord contained only two vessels, one vein and one artery on right side. Left umbilical artery was absent.

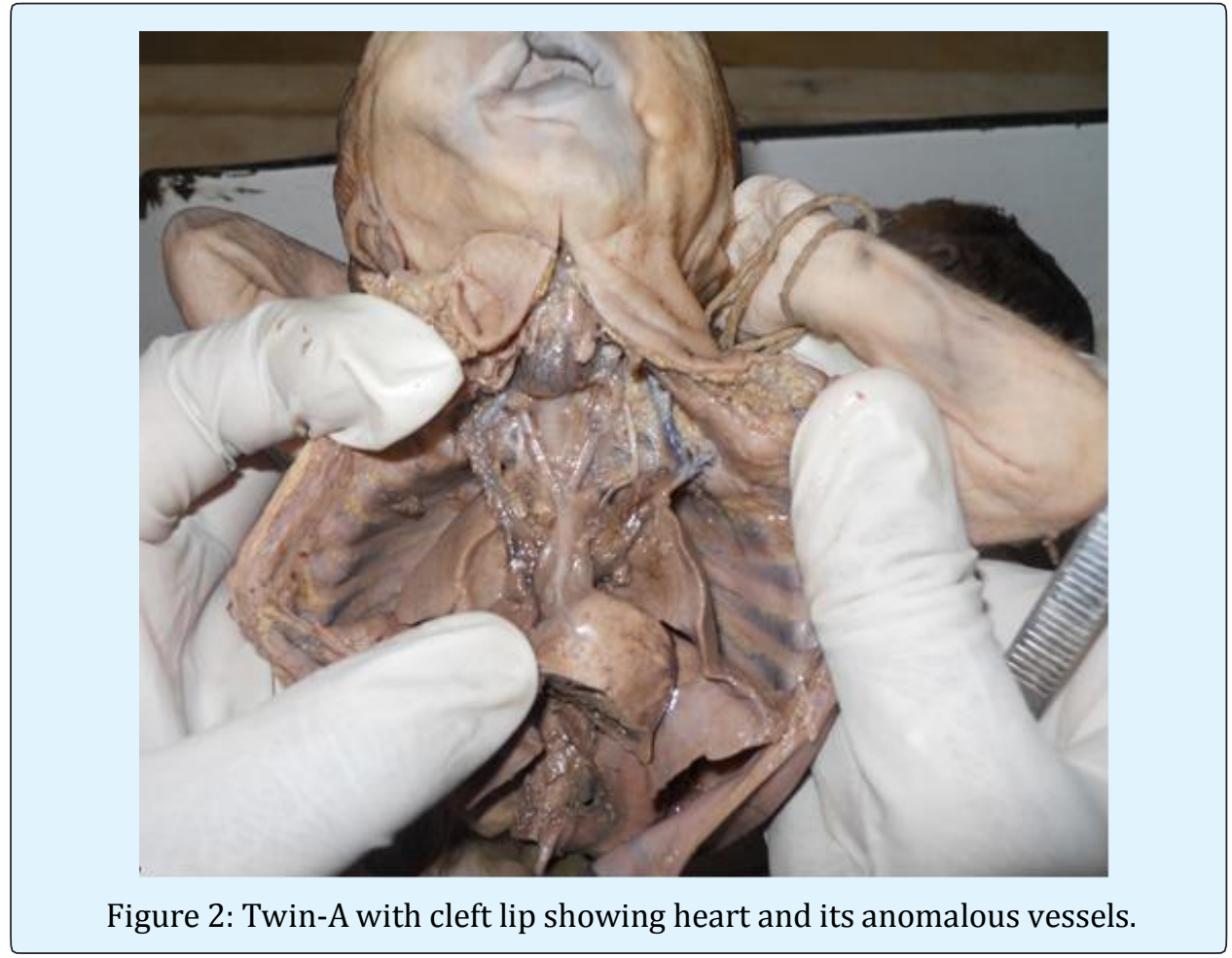

\section{Twin-B without Cleft Lip}

a. Here also origin of aorta and pulmonary artery were from single ventricle with incomplete spiral septum. Aortic arch gave rise to right brachiocephalic and left common carotid artery \& left subclavian artery.

b. Anomalies of systemic venous return were present. Right superior vena cava was absent with persistent left superior vena cava. It received hemiazygos, innominate, and jugular veins of both the sides. Persistent left superior vena cava returning to the coronary sinus which entered on left sided morphologically right atria. Azygos vein was absent in this side.

c. Inferior vena cava was separate for twin-B and opened into atrium of Twin-B along with pulmonary vein.

d. Now regarding abdominal cavity, it was single for both the twins with a common diaphragm. Genitilias and genitourinary system was normal. The gastrointestinal tract was malformed as following (Figure 3). 


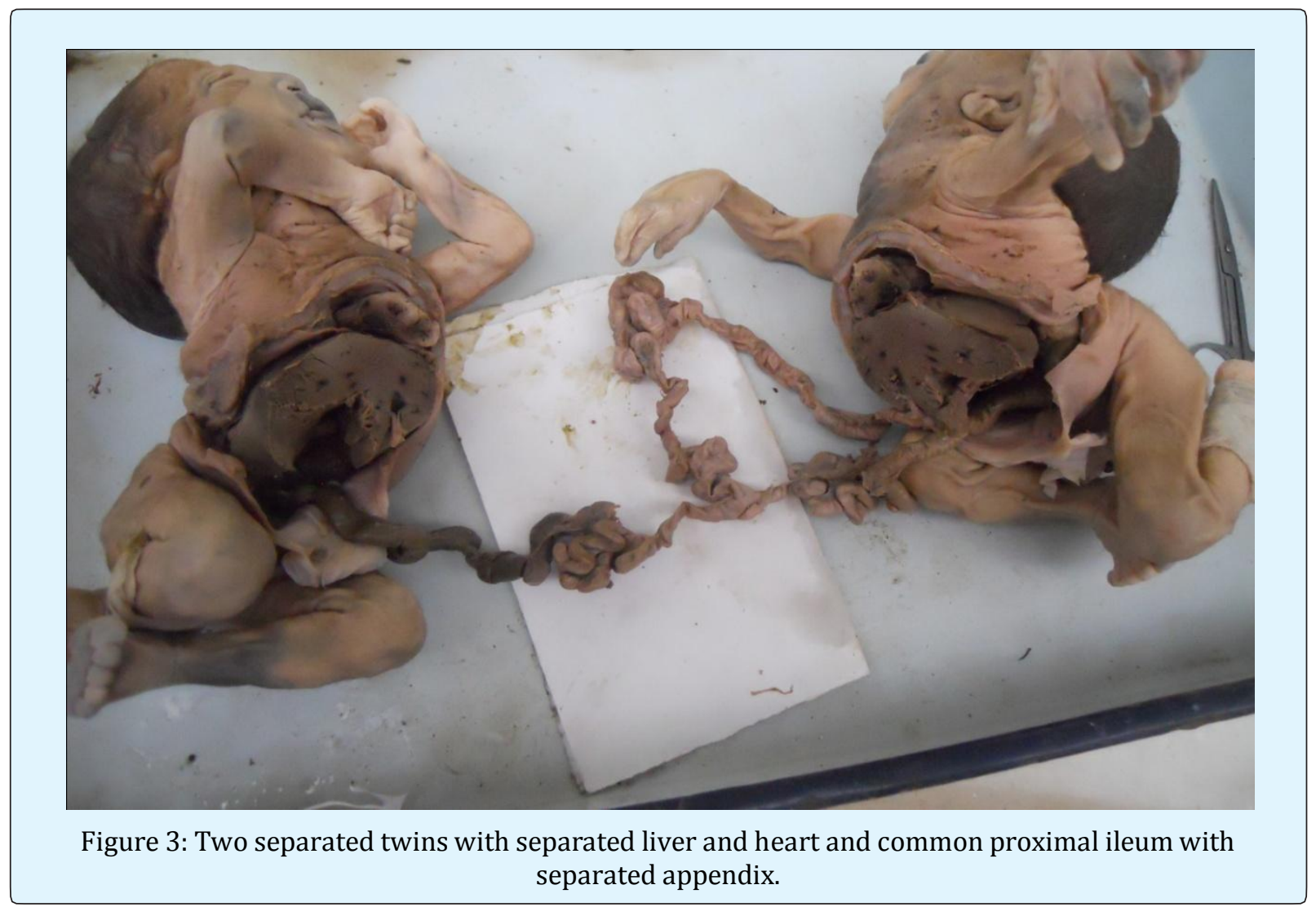

There were two separate foreguts, one for each twin but union of duodenum at second part, forming a common terminal duodenum with single ampulla of vater receiving single common bile duct from two semi annular pancreases. Then there were common jejunum and common proximal ileum with its subsequent division into two terminal ileum for each twin and that is at the level of vitello-intestinal duct. So, from the level of vitellointestinal duct, the rest of gut was separate for individual twin. Single common liver with fusion of anterior and posterior portions of porta-hepatis is much characteristic feature for the twins.

The placenta was monoamniotic, monochorionic and weighted $280 \mathrm{gm}$. The umbilical cord extended from the abdominal region of the twins and inserted centrally on the foetal surface. There were total of five umbilical vessels, two veins and three arteries. One vein and one artery for twin-A, and two arteries and one vein from twin-B.

\section{Discussion}

Conjoined twins are monozygotic or identical twins which develops from a single fertilized egg which splits into two embryos but do not fully separate from each other during the blastula stage between the $13^{\text {th }}$ to $15^{\text {th }}$ day after fertilization [8]. They are classified according to most prominent site of conjugation. The thoracopagus is the most common variety with an incidence of $0.5 \%$ and omphalopagus is the least common variety.

The earliest antenatal diagnosis of thoracopagus twins reported in the literature was made by transvaginal sonography as early as $8^{\text {th }}$ weeks of gestation. Even after the diagnosis, overall survival rate for conjoined twins is approximately $25 \%$ [9]. The overall incidence is higher in female with a ratio of 3:1.This is because, the $\mathrm{XX}$ Karyotype may confer a survival benefit and the process of X-inactivation overlaps with timing of monozygote twinning [10].

The actual pathogenesis is still not well defined but either incomplete fission of the developing embryo or the development of co-dominant axis with apposition of part of the axis that leads to conjunction [11-13].

After making the diagnosis of the conjoined twins, 3-D ultra-sonography, CT and MRI are the other methods to diagnose the characteristic and severity of abnormality. During early stages of pregnancy, usually in $1^{\text {st }}$ trimester, termination can be offered to the family. Surgical 
separation may range from simple procedure to very complex lengthy surgeries with good to bad prognostic outcome, depending upon the point of attachment and the internal organs they shared especially the degree of cardiac fusion. Most cases of separation are extremely risky and life threatening. For cardiac evaluation, full cardiac catheterization with selective angiography is essential before separation is considered.

\section{Conclusion}

Conjoined thoracopagus twins are associated with a high prenatal mortality. If they are diagnosed before viability, termination should be done with the consent of parents. A vaginal delivery is preferred for still birth and for those who do not survive. The degree of fusion of the heart determines the outcome.

\section{The Conflict of Interest}

The authors state that they have no conflict of interest with institution

\section{Ethical Approvals}

No ethical approval is required. Specimen was taken from pathology museum.

\section{Contribution}

Research is a collective work done by all the authors. First author have done the dissection part along with the help of other authors. All the references were collected together.

\section{References}

1. Rees AE, Vujanic GM, Williams WM (1993) Epidemic of conjoined twins in Cardiff. Br J Obstet Gynaecol 100(4): 388-391.

2. Filler RM (1986) Conjoined twins and their separation. Semin Perinatol 10(1): 82-91.

3. Spencer R (2000) Theoretical and analytical embryology of conjoined twins: part I: embryogenesis. Clin Anat 13(1): 36-53.
4. Spencer R, Robichaux WH (1998) Prosopothoracopagus conjoined twins and other cephalopagus-thoracopagus intermediates: case report and review of the literature. Pediatr Dev Pathol 1(2): 164-171.

5. Goldstein AM, Ticho BS, Fishman MC (1998) Patterning the heart's left-right axis: from zebrafish to man. Dev Genet 22(3): 278-287.

6. Abossolo T, Dancoisne P, Tuaillon J, Orvain E, Sommer JC, et al. (1994) Early prenatal diagnosis of asymmetric cephalothoracopagus twins. J Gynecol Obstet Biol Reprod (Paris) 23(1): 79-84.

7. Stone JL, Goodrich JT (2006) The craniopagus malformation: classification and implications for surgical separation. Brain 129(5): 1084-1095.

8. Chitnis S, Derom C, Vlietinck R, Derom R, Monteiro J, et al. (1999) X chromosome-inactivation patterns confirm the late timing of monoamniotic- MZ twinning. Am J Hum Genet 65(2): 570-571.

9. Levin M, Johnson RL, Stern CD, Kuehn M, Tabin C (1995) A molecular pathway determining left-right asymmetry in chick embryogenesis. Cell 82(5): 803814.

10. Ankur Aneja, Dayananda kumar Rajanna, Vikram narasimha reddy, Kamala retnam mayilvganan, Poornima pujar (2013) Conjoined Twins: A Rare Case of Thoraco-Omphalopagus. J clinical diagnostic reaserch 7(7): 1471-1472.

11. Saddler's TW Langman (2012) Langmans Medical Embryology, Phiadelphia, Lipincott Williams \& Wilkins, a Wolters Kluwer business 54-55.

12. Mehmet A, Osmanagaoglu, Turhan Aran, Suleyman Guven, Cavit Kart (2011) Thoracopagus Conjoined Twins: A Case Report. ISRN Obstetrics and Gynecology.

13. Samuel Milham (1966) Symmetrical conjoined twins: An analysis of the birth records of twenty-two sets. The Journal of Pediatrics 69(4): 643-647. 